\title{
More than bargained for: pneumomediastinum and subcutaneous emphysema associated with synthetic cannabinoid use
}

\author{
Richard Young, Andres Molina
}

Internal Medicine, University of Arizona, Tucson, Arizona, USA

\section{Correspondence to \\ Dr Richard Young, richardyoung@deptofmed. arizona.edu}

Accepted 20 November 2018

\section{DESCRIPTION}

Over the past decade, the USA has seen an increase in both availability and consumption of synthetic cannabinoid products. While traditional cannabinoid exposure in the form of marijuana is known to be associated with a host of complications, such as cannabinoid hyperemesis syndrome, new synthetic derivatives have been linked to a variety of different complications of toxicity. Mood elevation with psychosis, neurological complications, acute kidney injury and even death have been observed with the increased prevalence of these substances. ${ }^{1}$ Because of their over-the-counter availability and limited detectability via standard urine drug screens, increased use of synthetic cannabinoid products has been rising, and familiarising their associated complications is likely to be beneficial for providers when making a prompt and accurate diagnosis.

Patient is an 18-year-old man with a medical history of asthma (intermittent, well controlled) who presented with chest pain and significant palpable crepitus of the anterior chest extending to the posterior shoulders and superior abdomen after consuming synthetic marijuana (also known as spice). He stated that 1 day prior to admission, he used a water pipe to smoke synthetic marijuana and inhaled so aggressively that he

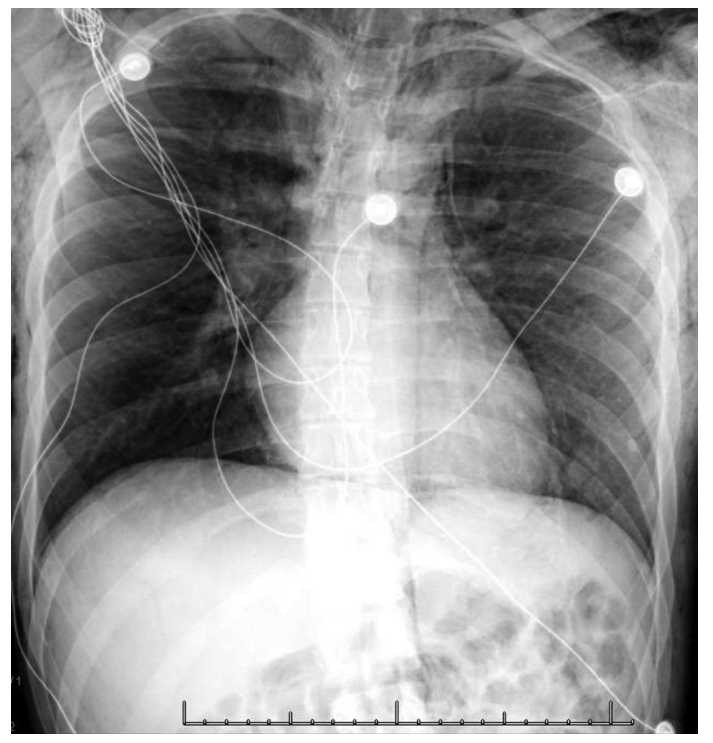

Figure 1 Chest radiograph demonstrating extensive pneumomediastinum, pneumopericardium and pneumoperitoneum. (Notable finding of 'continuous diaphragm' sign). experienced coughing fits severe enough to cause emesis. Patient was not in acute distress on presentation, and his lungs were clear to auscultation bilaterally. Plain radiograph of the chest revealed extensive pneumomediastinum, pneumopericardium and pneumoperitoneum (figure 1).

The patient was evaluated by thoracic surgery on arrival. Management goals for subcutaneous emphysema are directed at treating the underlying cause. The common sources include pneumothorax, barotrauma, gastrointestinal tract perforation and iatrogenic aetiologies. ${ }^{2}$ In this case, use of a water pipe and subsequent coughing, retching and emesis were provoking factors. Severe retching and coughing can act to increase airway pressures resulting in barotrauma or may incite oesophageal microperforations, both of which can result in subcutaneous emphysema on presentation. ${ }^{3}$ Because the patient was clinically stable on arrival and inciting causes were removed, emergent surgical intervention was deferred. Instead serial chest radiographs were ordered to monitor for progression of subcutaneous emphysema. Routine CT imaging was to be obtained for further characterisation of the gas in the patient's neck and chest. The patient was admitted to the internal medicine service. Initial interventions included administration of

Learning points

- Recreational, synthetic cannabinoid use is a growing industry in the USA. Based on our literature search, there is a limited amount of data available regarding complications associated with these substances, with minimal other international reports describing pneumomediastinum.

- Comprehensive imaging records associated with such presentations are sparse. We present a rare, documented case of pneumomediastinum and crepitus in presence of synthetic cannabinoid use.

- The need for appropriate identification of symptoms and history taking when working up a patient with suspected synthetic cannabinoid use is paramount. Once suspected, appropriate imaging in the form of radiograph, CT and consultation for appropriate intervention should be done promptly. 
IV antibiotics and IV proton pump inhibitor. He was made nil by mouth after presentation. In the event of clinical deterioration, thoracic surgery would re-evaluate the patient for emergent intervention. Otherwise, the subcutaneous air would reabsorb over time without the need for percutaneous drain. ${ }^{2}$ After beginning the above interventions, the patient reported feeling improved and requested to leave the hospital. Despite extensive counselling to stay, he signed out approximately 12 hours after presentation. Six hours after discharge, he was found wandering the streets in a confused state. On readmission, he admitted to cocaine use and synthetic cannabinoid consumption. Thereafter, he had an uncomplicated hospital course with serial chest X-rays revealing an improvement of subcutaneous air. CT imaging demonstrated no evidence of airway or gastrointestinal perforation. On final chest X-ray and outpatient follow-up, patient's subcutaneous emphysema had completely resolved.
Contributors RY: interviewed patient and participated in patient care and management, responsible for obtaining images and drafting first manuscript and admitted patient to hospital on both admissions. AM: obtained informed consen and participated in continuity of care of patient, reviewed manuscript and edited drafts prior to submission.

Funding The authors have not declared a specific grant for this research from any funding agency in the public, commercial or not-for-profit sectors.

Competing interests None declared.

Patient consent for publication Obtained.

Provenance and peer review Not commissioned; externally peer reviewed.

\section{REFERENCES}

1 Trecki J, Gerona RR, Schwartz MD, et al. Synthetic cannabinoid-related illnesses and deaths. N Eng/ J Med 2015;373:103-7.

2 Beck PL, Heitman SJ, Mody CH. Simple construction of a subcutaneous catheter for treatment of severe subcutaneous emphysema. Chest 2002;121:647-9.

3 Parker GS, Mosborg DA, Foley RW, et al. Spontaneous cervical and mediastinal emphysema. Laryngoscope 1990;100:938-40.

Copyright 2018 BMJ Publishing Group. All rights reserved. For permission to reuse any of this content visit

https://www.bmj.com/company/products-services/rights-and-licensing/permissions/

BMJ Case Report Fellows may re-use this article for personal use and teaching without any further permission.

Become a Fellow of BMJ Case Reports today and you can:

- Submit as many cases as you like

- Enjoy fast sympathetic peer review and rapid publication of accepted articles

- Access all the published articles

- Re-use any of the published material for personal use and teaching without further permission

For information on Institutional Fellowships contact consortiasales@bmjgroup.com

Visit casereports.bmj.com for more articles like this and to become a Fellow 